\title{
Comprehensive Two-Dimensional Gas Chromatography for Analysis of Volatile Compounds in Foods and Beverages
}

\author{
Juliane Elisa Welke ${ }^{a, b}$ and Cláudia Alcaraz Zini ${ }^{*, a}$ \\ ${ }^{a}$ Instituto de Química, Universidade Federal do Rio Grande do Sul, Av. Bento Gonçalves, 9500, \\ 91501-970 Porto Alegre-RS, Brazil \\ ${ }^{b}$ Instituto Federal de Educação, Ciência e Tecnologia Farroupilha, Rua Erechim 860, \\ 98280-000 Panambi-RS, Brazil
}

\begin{abstract}
A cromatografia gasosa bidimensional abrangente $(\mathrm{GC} \times \mathrm{GC})$ é uma técnica analítica relativamente nova, que tem sido amplamente empregada para análise de vários tipos de amostras complexas. A GC $\times \mathrm{GC}$ proporciona maior capacidade de pico, sensibilidade e resolução, quando comparada à cromatografia gasosa monodimensional (1D-GC). Além disso, a estruturação dos cromatogramas bidimensionais auxilia na identificação de classes de compostos. No que diz respeito à análise de alimentos e bebidas, a eficiência superior da $\mathrm{GC} \times \mathrm{GC}$ resulta em benefícios únicos quando comparada às técnicas analíticas disponíveis para os mais variados objetivos de análise: separação de grupos de compostos aroma-ativos, verificação de perfil cromatográfico, análise de compostos alvo ou identificação de componentes desconhecidos. Quando compostos aroma-ativos estão presentes em nível de traços, a $\mathrm{GC} \times \mathrm{GC}$ também pode ser empregada como uma técnica de alto potencial devido a sua sensibilidade superior. Tendo em vista que a fração volátil de muitos alimentos e bebidas pode determinar a aceitação ou rejeição destes produtos por parte do consumidor, a caracterização da mesma pode ser feita com base na composição destes compostos voláteis. Neste trabalho, as aplicações da $\mathrm{GC} \times \mathrm{GC}$ para análise de voláteis em alimentos e bebidas são apresentadas, desde a fase inicial de sua implementação até 2010. Alguns tópicos relacionados aos princípios da $\mathrm{GC} \times \mathrm{GC}$ foram também discutidos.
\end{abstract}

Comprehensive two-dimensional gas chromatography $(\mathrm{GC} \times \mathrm{GC})$ is a relatively new analytical technique, which has been widely used for the analysis of a variety of complex samples. GC $\times \mathrm{GC}$ offers increased peak capacity, higher sensitivity, and improved resolution when compared to conventional one-dimensional gas chromatography (1D-GC). In addition, it generates structured two-dimensional chromatograms, which aids in the identification of compound classes. The enhanced separation provided by $\mathrm{GC} \times \mathrm{GC}$ has been a distinctive benefit when it is compared to other available analytical techniques that deal with the analysis of food and beverages, irrespective of the goal of the analysis, i.e. aroma group-type separation and fingerprinting, target-volatile compound analysis or identification of unknowns. When trace amounts of aroma active compounds are present, $\mathrm{GC} \times \mathrm{GC}$ may also be used as a very powerful tool for their analysis due to its higher sensitivity. As volatile fractions may determine the acceptance or rejection of many foods and beverages by the consumer, the characterization of these products may be done having volatile composition as a basis. Applications of $\mathrm{GC} \times \mathrm{GC}$ for the analysis of volatiles of foods and beverages were revised since the emergence of this technique until 2010. Some topics related to principles of $\mathrm{GC} \times \mathrm{GC}$ were also discussed.

Keywords: comprehensive two-dimensional gas chromatography, GC×GC, flavour analysis, aroma analysis

\section{Introduction}

The study of volatile fractions in foods and beverages has become necessary since volatiles make the major

*e-mail: cazini@iq.ufrgs.br contribution to the consumer's overall perception of the quality of these products. Thus, the volatile compounds largely determine the acceptance or rejection of many products. Flavour is defined as the sensation arising from the integration or interplay of signals produced as consequence of smell and taste. ${ }^{1}$ Several volatiles have 
been identified as important contributors to the flavour of food and beverages. ${ }^{2-5}$ In addition, compounds known as off-flavours are caused by the presence of volatiles often associated to microbial contamination, oxidative or enzymatic process that give unpleasant odor and taste. ${ }^{6}$

The characterization and differentiation of foods and beverages may be possible on the basis of their volatile fraction. There is wide evidence in numerous studies that it is possible to establish clear relationships among the volatile fraction of these products and the following aspects: the raw material employed, the origin of the raw material and its production process. $2,3,3,7,7$,

The determination of volatile compounds is normally performed by gas chromatography (GC) and the following aspects should be considered in the sample preparation: (i) the low concentration and great chemical variety of the compounds of interest and (ii) the great complexity of the matrices where these compounds are found. ${ }^{9}$

The complete resolution of the analytes in a minimum analysis time must always be the primary objective in any chromatographic separation. Ideally, it must ensure that pure analyte bands are delivered to the detector. The direct consequence of insufficient resolution is that many elution bands will be the summation of two or more overlapping analytes. This leads to possible errors in the identification and quantification of target components. ${ }^{10}$ One-dimensional capillary gas chromatography (1D-GC) is routinely used to separate the volatile constituents of food and beverage samples. The complex nature of these samples - that includes compounds of many different kinds of chemical classes - requires long GC run times to obtain the maximum separating power. Furthermore, deep analysis of the chromatograms frequently indicates that some peaks are the result of two or more co-eluting compounds. As a consequence of chromatographic co-elutions, reliable mass spectrometric identification may not be possible. In addition, the aroma-active compounds are usually present in trace amounts and are not usually the major volatile constituents of foods and beverages. ${ }^{11,12}$

The use of heart-cut or two-dimensional gas chromatography (GC-GC) helps solving some of the above mentioned problems. In this technique, a limited number of fractions of first-column eluate is transferred to a second column. ${ }^{13}$ The GC-GC is successful in a target-analysis situation, where only some fractions contain all compounds of interest. When, on the other hand, the entire sample needs to be transferred to a second column, this technique is too time-consuming and complicated. ${ }^{14}$

In the past decade, comprehensive two-dimensional gas chromatography $(\mathrm{GC} \times \mathrm{GC})$ emerged as a powerful analytical technique and an excellent choice to unravel the composition of complex samples. The interesting aspect of $\mathrm{GC} \times \mathrm{GC}$, as opposed to a heart-cut technique, is that the entire sample is subjected to two independent separations and the two-dimensional separation is completed in the run time of the first separation. Considerably more information about sample constituents is provided, and the time of analysis is seriously reduced..$^{15}$

The enhanced separation provided by $\mathrm{GC} \times \mathrm{GC}$ has been a distinctive benefit in the analysis of food and beverages, irrespective of the goal of analysis, i.e. aroma group-type separation and fingerprinting, ${ }^{16}$ target-volatile compound analysis $^{12}$ or identification of unknowns. ${ }^{8}$

\section{Instrumentation}

Ideally, the GCxGC employs two orthogonal mechanisms to separate the constituents of the sample within a single analysis. The technique is based on application of two GC columns coated with different stationary phases connected in series through a special interface, the so-called modulator. ${ }^{17}$

The modulator is the heart of the instrument because it ensures that the separation is both comprehensive (the entire sample is subjected to both separation dimensions) and multidimensional (separation accomplished in one dimension is not lost in the other dimension). ${ }^{18}$ The modulator (i) accumulates, traps (ii) refocuses and (iii) rapidly releases the adjacent fractions of the firstdimension column..$^{19}$ The time required to complete this process is defined as the modulation period (generally in the 4-8 s range). The cryogenic-jet modulators are the latest type and they use liquid carbon dioxide or nitrogen for cooling. The cryogenic modulators are used to create the required retention/release temperature differences. ${ }^{20-23}$ The modulation time period is consistent with the separation time in the second column, which minimizes the broadening of the compressed band, and also limits the wrap-around of analytes. ${ }^{24,25}$ As a consequence, the signal-to-noise ratio (and sensitivity as well) is significantly enhanced (reportedly 10 times or more), compared to onedimensional gas chromatography (1D-GC). ${ }^{26,27}$

For many applications, the primary column is typically nonpolar and separation is essentially related to different boiling points. Each individual modulation undergoes a further rapid analysis, generally on a polar column, where analytes are resolved on the basis of dissimilar polaritybased interactions. Although the separation of the highest number of components per unit of time and the isolation of target analytes is the main objective in any GC method, other aspects must be considered in $\mathrm{GC} \times \mathrm{GC}$, such as the formation of ordered patterns of structurally related 
compounds and the avoidance of wrap-around among analytes. $^{16,28}$

During trial-and-error method optimization, the primary nonpolar and secondary polar combination is usually the first tested. But, this option is not always the most suitable choice, and other column combinations might produce a better result. ${ }^{5,11,29-31}$ Cordero et al. ${ }^{16}$ tested three column sets to optimize separation of volatiles of roasted hazelnuts. The different orthogonal and nonorthogonal column sets were combined as follows: column set 1 consisted of a firstdimension ( $\left.{ }^{1} \mathrm{D}\right)$ SE52 column (95\% polydimethylsiloxane, $5 \%$ phenyl) coupled with a second dimension $\left({ }^{2} \mathrm{D}\right)$ OV1701 column (86\% polydimethylsiloxane, 7\% phenyl, 7\% cyanopropyl); column set 2 consisted of a ${ }^{1} \mathrm{D}$ SE52 column coupled with a ${ }^{2} \mathrm{D}$ OV17 column $(50 \%$ polydimethylsiloxane, $50 \%$ phenyl) and column set 3 consisted of a ${ }^{1} \mathrm{D}$ CW20 M column (100\% polyethylene glycol) coupled with a ${ }^{2}$ D OV1701 (Figure 1). Occupation of the two-dimensional (2D) plane was maximized when column set 2 was used. However, the structured patterns of chemically correlated groups were partially and, in some cases, completely disordered, because the higher retention in the ${ }^{2} \mathrm{D}$ generated the phenomenon of wraparound, in particular for the polar analytes, such as alcohols and furans. In polar $\times$ nonpolar configuration (set 3 ), several classes of compounds were displayed in ordered structures. With this set, polar analytes, such as linear acids and aldehydes, were more strongly retained on the ${ }^{1}$ D. Comparing columns of sets 1 and 3 , the occupation of the 2D plane was better in set 1 , where chemically correlated groups ( $n$-alkanes, alcohols, aldehydes, acids)

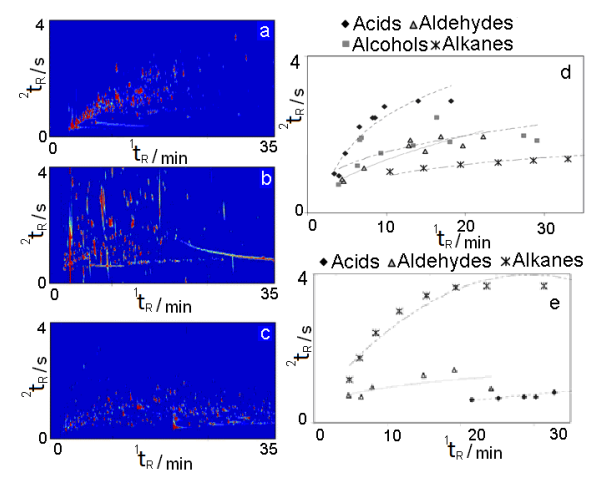

Figure 1.2D patterns of the volatile fraction of a roasted Corylus avellana L. sample from Piedmont obtained with different column configurations: (a) column set 1 - SE52 column (95\% polydimethylsiloxane, 5\% phenyl) coupled with a second dimension ( $\left.{ }^{2} \mathrm{D}\right)$ OV1701 column $(86 \%$ polydimethylsiloxane, $7 \%$ phenyl, $7 \%$ cyanopropyl); (b) column set 2 SE52 column coupled with a ${ }^{2}$ D OV17 column (50\% polydimethylsiloxane, $50 \%$ phenyl); (c) column set 3 - CW20 M column (100\% polyethylene glycol) coupled with a ${ }^{2} \mathrm{D}$ OV1701; (d) Group of components of the volatile fraction of the Piedmontese roasted sample located over the $2 \mathrm{D}$ plane with elution bands(dotted lines) analyzed with (d) column set 1 and (e) column set 3 . Adapted from reference 16 . were structurally ordered along the $2 \mathrm{D}$ plane. The column configuration 1 was adopted by the authors for the following experiments because of its suitable analyte resolution capability in both chromatographic dimensions.

In $\mathrm{GC} \times \mathrm{GC}$, the second-dimension separation must be fast and the elution of all analytes of a modulated narrow pulse should be completed before the first compounds contained in the next pulse reach the detector. Peak widths depend on the type of modulator used, column dimensions, gas flow and second-dimension retention time. The narrow peaks require fast detectors with a small internal volume and a short rise time in order to achieve a proper reconstruction of the second-dimension chromatograms. The most commonly used detection systems employed for identification of volatile compounds in food and beverages has been flame ionization detector (FID) and mass spectrometry detector (MS), ${ }^{4,16,26,29}$ especially time of flight mass spectrometry (TOFMS).,31,32 The quadrupole mass spectrometric detector (qMS) has been less used in analysis of volatile compounds than TOFMS detector. For applications with a limited mass range (100-300 Da), rapidscanning qMS is a useful alternative to TOFMS. ${ }^{5}$ However, whenever the target analytes cover a broad mass range and when the searching for unknown compounds is a key aspect, the use of a TOFMS instrument becomes necessary. TOFMS instruments acquire 50 or more mass spectra per second, which is required for the proper reconstruction of the very fast second-dimension peaks, and provide reliable deconvolution of overlapping peaks. ${ }^{33}$ Selective detectors, such as nitrogen-phosphorus detector (NPD) - which has a selective response to organic compounds containing nitrogen and/or phosphorus - were also employed for volatile analysis, e.g. detection of methoxypyrazines in wines by Ryan et al. ${ }^{34}$

There is general agreement regarding the main advantages of $\mathrm{GC} \times \mathrm{GC}$ over conventional $1 \mathrm{D}-\mathrm{GC}$ and also GC-GC in the literature. ${ }^{8,11,12}$ In GC $\times$ GC, the peak capacity is much higher, which yields a distinctly improved separation not only between analytes but also from interfering matrix constituents. The detectability is improved due to the refocusing process in the modulator and due to the improved analyte separation. ${ }^{2,35}$ One of the main advantages of $\mathrm{GC} \times \mathrm{GC}$ is this ordered retention of structurally related compounds shown in the contour plot, which allows the immediate recognition of chemical classes present in a complex sample, as in a fingerprint. ${ }^{36}$

The literature about the use of comprehensive two dimensional gas chromatography applied to determination of volatile compounds related to aroma of beverages and food was revised. The present paper will focus attention on analysis of beverages, including wine, juice, cachaça, 
liquor and coffee and also foodstuff such as fruits, dairy products, honey, hazelnut and roast beef. Volatiles found in olive oil and spices were also included in this review.

\section{Beverages and other Foodstuff}

The qualitative and quantitative study of volatiles of beverages results in an important database for ensuring process continuity and product authenticity. Analysis of volatile compounds is generally used to characterize different types of beverages or varieties of a certain beverage type. Each volatile compound has a contribution for flavour that is determined by both its concentration and its unique sensory threshold value. This means that levels of the abundant compounds cannot be linked to perceived flavour, as the odor impact of low threshold trace compounds can often be more dominant. ${ }^{37}$

\subsection{Wine}

Methoxypyrazines are compounds with very low threshold values that occur in some Vitis vinifera grapes and their wines. 2-isobutyl-3-methoxypyrazine (IBMP) is responsible for imparting the aroma described as vegetative, green, bell-pepper and capsicum to some wines made with Cabernet Sauvignon grapes. ${ }^{38}$

Ryan et al..$^{34}$ extracted methoxypyrazines from wine by headspace-solid phase microextraction (HS-SPME) and analyzed with both $\mathrm{GC} \times \mathrm{GC}-\mathrm{NPD}$ and $\mathrm{GC} \times \mathrm{GC} /$ TOFMS in order to compare the capabilities of the two detectors for the detection of IBMP in particular. Stable isotope dilution was performed to quantify IBMP using deuterium labelled 2-isobutyl- $\left({ }^{2} \mathrm{H}_{3}\right)$ methoxypyrazine (d3IBMP) as the internal standard. The resolution of the two analogues was facilitated by the deconvolution capabilities of TOFMS. Analysis by GC $\times$ GC-NPD enabled limits of detection (LOD) of $0.5 \mathrm{ng} \mathrm{L}^{-1}$ for the quantifitation of IBMP, which was better than that obtained using $\mathrm{GC} \times \mathrm{GC} /$ TOFMS (1.95 $\left.\mathrm{ng} \mathrm{L}^{-1}\right)$. Nevertheless, both methods were adequately sensitive for real wine analysis and yielded comparable quantification levels of IBMP concentrations of 26.1 and $27.8 \mathrm{ng} \mathrm{L}^{-1}$, respectively, from a Sauvignon blanc wine.

Ryona et al. ${ }^{39}$ described a protocol for analysis of the herbaceous smelling 3-alkyl-2-methoxypyrazines (MP) in whole berries that predicts MP concentration in resultant red wines. The quantification of IBMP and 3-isopropyl-2-methoxypyrazine (IPMP) in grapes and wines was done by $\mathrm{GC} \times \mathrm{GC} / \mathrm{TOFMS}$, which successfully resolved interferences that coeluted with the IPMP in the first dimension. The first interference, present in blanks was tentatively identified as a silylated phenyl compound and was derived from either column or septum bleed. The second interference was identified as a monoterpene. These interferences are resolved by the second dimension WAX column. The LOD for IBMP and IPMP were $0.6 \mathrm{ng} \mathrm{kg}^{-1}$ and $1.8 \mathrm{ng} \mathrm{kg}^{-1}$ in preveraison berries, and $1.2 \mathrm{ng} \mathrm{kg}^{-1}$ and $0.9 \mathrm{ng} \mathrm{kg}^{-1}$ in harvest-ripe berries. Sixteen lots of Cabernet Franc berries and the resulting wines were analyzed. IBMP concentrations in whole berries ranged from undetectable to $18.4 \mathrm{ng} \mathrm{kg}^{-1}$ and from undetectable to $14.5 \mathrm{ng} \mathrm{L}^{-1}$ in wines. IPMP was not detectable $\left(<0.6 \mathrm{ng} \mathrm{kg}^{-1}\right)$ in any berry and wine sample.

Volatiles of Brazilian base wines have been studied by our group. The volatiles extraction is done by HSSPME using a DVB/CAR/PDMS coating. For GC $\times$ GC analysis three column sets were tested. The conventional non-polar $\times$ polar set was initially evaluated by using the column combination DB- $5 \times$ DB-WAX, but results were not satisfactory, since the separation of many polar analytes could not be achieved. Using an inverse column set, the separation space was poorly occupied. Finally, a better distribution of the volatiles in the separation space was achieved using a polar (DB-WAX) $\times$ mediumpolar (DB-17ms) column set with GC $\times$ GC/TOFMS and GC $\times$ GC-FID. An example of analytical advantage obtained with $\mathrm{GC} \times \mathrm{GC}$ is the separation of some compounds, such as ethyl butanoate, ethyl isobutyrate and an unknown compound, which coelute in 1D-GC. Some wine flavour marker compounds were chosen for quantitative analysis by GC, which was performed using a FID, as coelutions were resolved. Ethyl esters were the main compounds found in Brazilian base wine. Higher concentrations were found for ethyl acetate, ethyl butanoate, ethyl hexanoate, ethyl octanoate and ethyl decanoate.

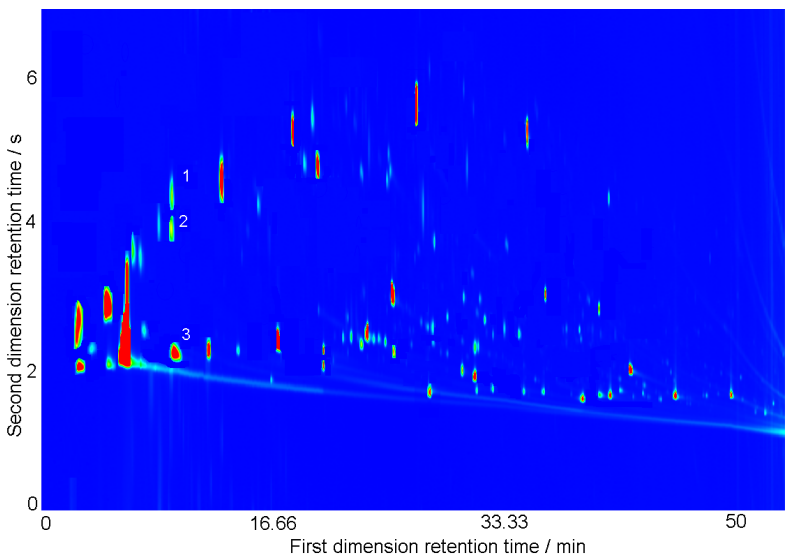

Figure 2. $\mathrm{GC} \times \mathrm{GC}$ color plot (see online) of a base wine obtained with a polar $($ DB-WAX) $\times$ medium-polar $(\mathrm{DB}-17 \mathrm{~ms})$ column set. Compounds designated as (1) ethyl butanoate, (2) ethyl isobutyrate and (3) unknown compound coeluting in $1 \mathrm{D}-\mathrm{GC}$ were separated using $\mathrm{GC} \times \mathrm{GC}$ (results not published yet). 


\subsection{Lemon juice and lemon-flavored beverages}

Komura $^{40}$ analyzed fresh lemon juice and lemonflavored beverages by GC $\times$ GC-FID with a non-polar $\times$ polar column combination. The identification of components in 2D plots was performed by comparison of peak positions of authentic standards and comparison with 1D-GC profile. However, without the aid of mass spectral data, only 24 components were identified and a large number of components remained unassigned due to lack of further structural information. In some beverages, compounds such as $\rho$-methylacetophenone and $\rho$-cymen- 8 -ol were present, which are indicative of deterioration.

\subsection{Cachaça}

The Brazilian sugar spirit, popularly named as cachaça is a liquor distilled directly from the fermented juice of unrefined sugarcane. Cardeal et al. ${ }^{3}$ analyzed aroma compounds of cachaça using $85 \mu \mathrm{m}$ polyacrylate (PA) HS-SPME fiber and GC $\times$ GC-TOFMS. The aging process of cachaça in different wood materials was characterized through fingerprint similarity observations. The authors used visual comparison and retention time comparison to identify co-incident and different peaks between samples. For quality control purposes, a simple observation of the contour plots obtained can allow the identification of the type of wood used during aging process, without further statistical treatment or peak identification (Figure 3). Each wood type generates a different flavour note to the original product, which was clearly visualized in the contour plots. Apparently the contribution of each wood to the cachaça volatile composition during the storage period varies significantly, thereby producing distinguishable contour plots.

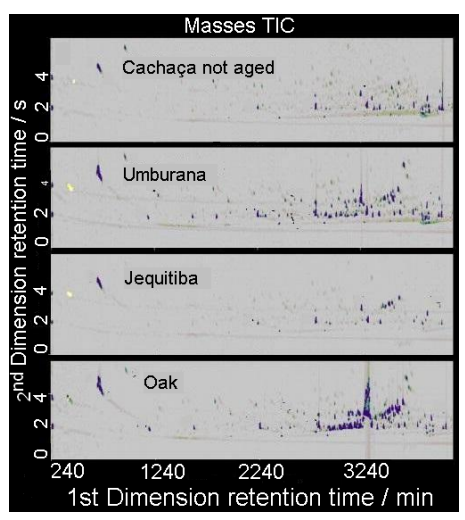

Figure 3. GC $\times$ GC-TOFMS contour plots of SPME headspace extracts showing a cachaça sample aged in three different wood materials. The uppermost contour plot shows the original cachaça (not aged) and the three lower contour plots were obtained after an ageing period in wood barrel material. Adapted from reference 3 .
Usually, cachaça made by artisans use physical filters to remove solid impurities from the casks. In addition, the use of an ion exchange resin after the alembic distillation to reduce copper content and a charcoal filter to reduce the acid content is reported by the industry. Effects of bidistillation process and the use of charcoal filtration in production of cachaça were investigated by Souza and co-workers. ${ }^{3}$ Volatile compounds were collected and concentrated onto $85 \mu \mathrm{m}$ PA SPME fiber and analyzed using $\mathrm{GC} \times \mathrm{GC} / \mathrm{TOFMS}$ on a non-polar $($ BPX5) $\times$ polar $($ BP20) column set. More than 100 compounds, comprising various homologous series were tentatively identified using MS library matching and comparison with 1D-GC retention indices. The cachaça obtained from the bidistillation process presents a very different composition of volatiles compared with the one derived from single distillation. Many homologous series identified in the single distilled sample are not present in bidistilled sample. Figure 4 displays the 2D plots of a cachaça sample taken before resin filter (Figure 4a), after resin filter, but before charcoal filter (Figure $4 b$ ), and after charcoal filter (Figure 4c). Comparison of the 2D plots of cachaça after and before the resin treatment confirms that there is not a great difference in the volatile composition. Figure $3 \mathrm{c}$ shows that passage through the charcoal filter also did not change the volatile content of cachaça significantly; although the signal intensity of some compounds was reduced, but without complete loss of compounds of each group.

The volatile profiles of various spirits such as cachaça, rum, vodka, whisky, gim, tequila and flavoured liqueurs were evaluated by Cardeal and Marriott ${ }^{32}$ using $85 \mu \mathrm{m}$ PA SPME fiber and GC $\times$ GC-TOFMS with a bidimensional non-polar $\times$ polar column set. Groups of compounds were present in well-defined regions of the 2D separation space in each beverage, making it possible to recognize the differences and similarities among the spirit samples. Furthermore, the 2D plots - either as contours or as peak apex plots - can be used as a fingerprint analysis, to differentiate samples of different producers or geographical locations, to detect if spirit is aged or unaged or to search adulterations.

\subsection{Liquor}

Chinese liquor is one of the oldest distillates in the world. It is usually fermented from grains, mainly sorghum, wheat, rice and corn. After several months or years of fermentation, the liquor is distilled. The fresh distillates need to be aged for several years in order to develop the balanced aroma. ${ }^{41} \mathrm{Zhu}$ et al. ${ }^{31}$ showed the advantages of $\mathrm{GC} \times \mathrm{GC}$ separation in comparison with 


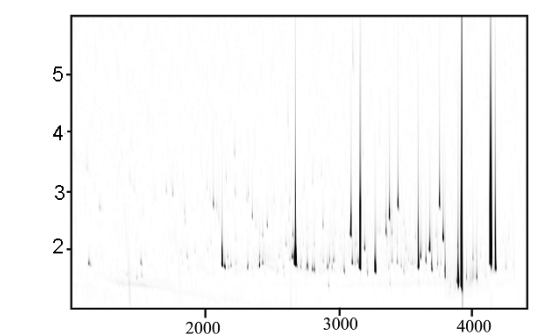

(a)

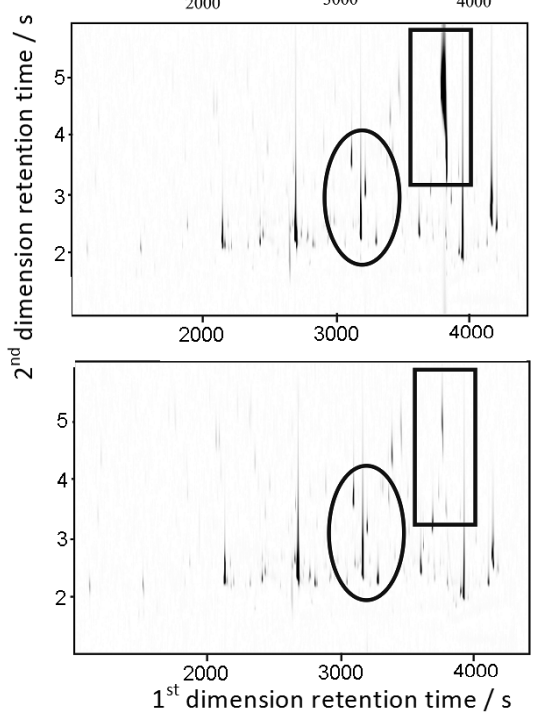

(b)

(c)

Figure 4. GC $\times$ GC-TOFMS total ion chromatogram (TIC) of cachaça (a) before the ion exchange resin; (b) after ion exchange resin but before charcoal filter and (c) after the charcoal filter. The circled regions highlight a section of 2D space where compounds have an apparent similar response and position. The boxed region points out the phthalate compound (b), which is absent in sample after the charcoal filter, according to the authors (c).Adapted from Souza et $_{\text {al. }}{ }^{42}$

1D-GC in analysis of Moutai Chinese liquor, as overlaid peaks in 1D-GC showed up as resolved peaks in $\mathrm{GC} \times \mathrm{GC}$. More peaks were detected summing up a total of 528 components, including organic acids, alcohols, esteres, ketones, aldehydes, acetals, lactones, nitrogen-containing and sulfur-containing compounds. These components were identified by TOFMS software with the help of information gathered from ordered chromatogram structure and retention index database developed in this study. Response was also greatly increased in $\mathrm{GC} \times \mathrm{GC}$ chromatogram, due to the focusing effect of the modulation and, as a consequence, many trace components in the liquor sample which were not detected in 1D-GC were sensitively determined in $\mathrm{GC} \times \mathrm{GC}$. The $\mathrm{GC} \times \mathrm{GC}-$ FID contour plot in different column sets are shown in Figure 5. According to the authors (Figure 5a), poor separation and asymmetric peaks were obtained on the two-dimensional plane using the normal $\mathrm{GC} \times \mathrm{GC}$ column combination (non-polar as the first column and a polar column as the second column). In figure $5 \mathrm{~b}$, the peaks are distributed over the whole two-dimensional plane, and the resolution and symmetry of peaks improved.

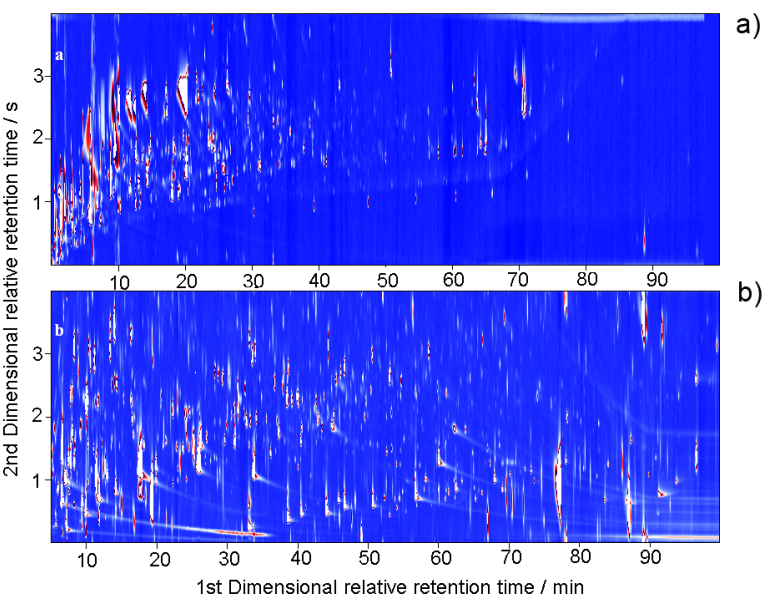

Figure 5. GC $\times$ GC-FID contour plots of Moutai liquor in different column sets: (a) non-polar (DB-petro) $\times$ polar (DB-1701); (b) polar $($ HP-innowax $) \times$ non-polar $($ DB-1701). Adapted from reference 31 .

\subsection{Coffee}

Coffee is one of the most complex food matrices. Coffee bean's chemical composition depends on several factors, such as species and variety of bean, geographic origin, soil conditions and storage of the beans, as well as time and temperature of the roasting procedure. Roasted bean is characterized by 800 components present in a vast concentration range. Several aroma constituents of coffee are products of Maillard reaction, a thermally induced reaction between amino acids and reducing sugars. Most volatiles are derived from non-volatile compounds of the green bean which break down and react during roasting. Commonly, fatty, green, lactonic and terpene-like notes characterize green coffee beans, while sweet, sulphurous and amino odors develop during roasting. ${ }^{43}$

Mondello et al. ${ }^{30}$ analyzed Arabica (Coffea arabica) and Robusta (Coffea canephora ex Froehner) varieties of coffee that have acquired worldwide economic importance by a simple sampling procedure using HS-SPME and GC $\times$ GC-FID for volatiles separation. A polar $\times$ non-polar column combination was used because of many fairly polar analytes that are present in headspace. About 1000 separated analytes showed up in the 2D separation space as against only about 200 in conventional GC/MS. Even without TOFMS detection being available, the authors reported some remarkable differences between volatiles of the two varieties. The coffee volatiles were characterized by a higher amount of furfurylpyrroles and lower amount of phenols and alkylpyrroles. Figure 6 shows part of a highly structured GC×GC-FID chromatogram. The pyrazines display a specific pattern in the $2 \mathrm{D}$ plane, as pyrazine ring systems with the same degree of alkyl carbon substitution tend to align themselves with second dimension elution 
times which gradually decrease as the GC oven temperature increases. This permits detailed characterization of the pyrazine fraction which plays a major role in coffee aroma profile.

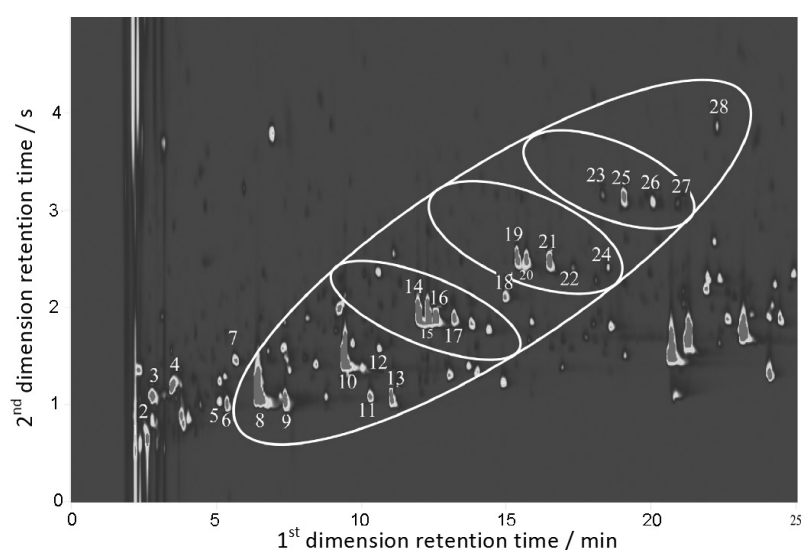

Figure 6. Part of GC $\times$ GC-FID chromatogram of roasted Arabica coffee beans using a SupelcoWax-10 × SPB-5 (Supelco, USA) column set. Compounds: (2) 2,5-dimethylfuran, (3) 2-butanone, (4) 2-butanone, (5) 2-methyltiophene, (6) n-methylpyrrole, (7) 2-vinyl-5-methylfuran, (8) pyridine, (9) pyrazine, (10) 2-methylpyrazine, (11) 4-methylthiazole, (12) 3-picoline, (13) acetol, (14, 15 and 17) dimethylpyrazine, (16 and 18) ethylpyrazine, (19, 20, 22) ethylmethylpyrazine, (21) 2,3,5-trimethylpyrazine, (23 and 26) diethylpyrazine, (24) 3-n-propylpyrazine, (25 and 27) ethyldimethylpyrazine. Adapted from reference 30 .

The volatile headspace of Arabica and Robusta varieties of coffee was sampled by SPME and analyzed using GC $\times$ GC by Ryan et al. ${ }^{5}$ Two distinct column set combinations were investigated: a polar x non-polar (set 1) and non-polar x polar (set 2) configuration. The volatile profile obtained with the polar $\times$ non-polar column set was superior as it showed a greater number of analyte peaks. These peaks presented in Figure 7a are efficiently distributed along the primary retention axis, which indicates that the polar first column is more effective in separating the polar constituents over a broader elution range, resulting in more separation space being used. Mass spectra of components were obtained by $\mathrm{GC} \times \mathrm{GC} / \mathrm{qMS}$ and $\mathrm{GC} \times \mathrm{GC}-$ TOFMS. This is not the case for the profile achieved using column set 2 (Figure $7 \mathrm{~b}$ ), where the separation space is redundant beyond $3000 \mathrm{~s}$ and the poorly retained polar solutes on the non-polar first dimension causes reduced retention, significant component overlap and low elution temperatures. Two dimensional contour plots for the different column sets are presented in Figure $7 \mathrm{c}$ and $7 d$ and show the dense peak clustering from 200 to $1000 \mathrm{~s}$ on the column set 2 . The results obtained from qMS analysis were in agreement with the findings of Shellie et al. ${ }^{44}$ who reported that qMS operated at reduced mass scanning range can be successfully coupled to $\mathrm{GC} \times \mathrm{GC}$ separations and offers a viable alternative to GC×GC-TOFMS analysis for some specific compounds. However, it must be recognized that maximum sample information can only be derived through full mass range scanning capabilities, afforded by TOFMS detection.
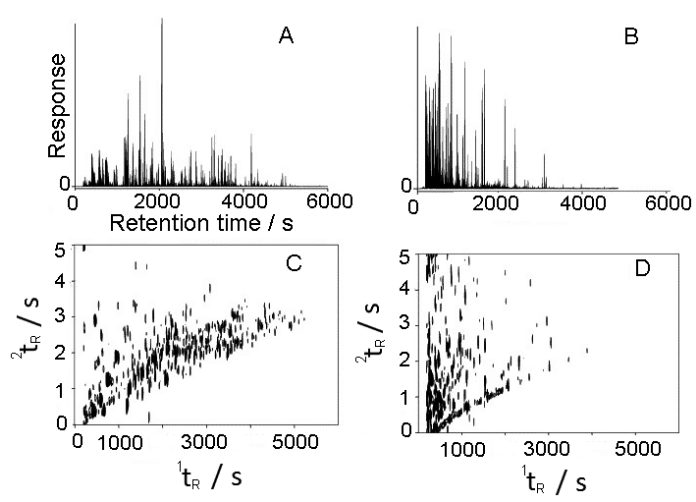

Figure 7. Total ion chromatograms (TIC) for Arabica coffee using polar $\times$ non-polar column (set 1) (A) and non-polar $\times$ polar (set 2) (B), and their respective contour plots $(\mathrm{C}$ and $\mathrm{D})$. Contour level setting for $(\mathrm{C})$ was from 10,000 at intervals of 15,000 , and from 5000 for (D), where responses are TIC sensitivities. Adapted from reference 5 .

\subsection{Barley}

Barley coffee is one of the most common coffee substitutes, appreciated for its high content of flavour, refreshing properties and low caffeine content. As other coffee beverages, it is prepared from grinded beans and water. The roasting process of the cereals forms a great number of volatile constituents belonging to different classes, such as pyrazines, furans, ketones and aldehydes. Bianchi et al. ${ }^{11}$ analyzed volatile compounds of roasted barley used in the production of coffee using SPME followed by GC/MS and GC×GC/TOFMS, respectively. The conventional nonpolar $\times$ polar set was initially evaluated by using the column combination HP5-MS $\times$ BPX-50. Here, the obtained results were also not satisfactory, since the separation of many polar analytes could not be achieved. In contrast, roasted barley components occupied a larger region of the separation space when the inverse column set DB-WAX $\times$ BPX-50 was employed. Sixty-four compounds were identified with the polar $\times$ nonpolar column set in a $\mathrm{GC} \times \mathrm{GC} / \mathrm{TOFMS}$, whereas only 40 volatiles were identified by $\mathrm{GC} / \mathrm{MS} .^{11}$

\subsection{Fruits}

The flavour of fruits is originated from carbohydrates, proteins, fatty acids, vitamins and minerals. As well-known for other food matrices, the complex volatile fraction of fruits is composed of a wide variety of compounds 
belonging to several chemical classes. Thus, an individual fruit may have a hundred of different volatile compounds, which also differ according to the fruit's ripening stage. ${ }^{45}$

Many compounds present in strawberry fruits are chiral and they can exist as racemates or in specific enantiomeric ratios. Enantiomers of a particular compound can exhibit vastly different sensory properties, for example the aroma of the $S$-enantiomer of 2-methyl butyric acid has been described as fruity and sweet. Conversely, the aroma of the R-enantiomer has been described as cheesy and sweat-like. ${ }^{46}$ Enantiomeric ratios may also offer information on varietal differentiation. Williams et al. ${ }^{4}$ used chiral GC $\times$ GC-FID with two directly coupled enantioselective first-dimension columns and a more polar column in a second dimension (BPX50, 50\% phenyl polysilphenylene-siloxane) to analyze strawberry volatiles sampled by HS-SPME. Two strawberry cultivars were differentiated and the effect of post-harvest storage on volatile composition of the fruit was evaluated. Figure 8 depicts both the expanded modulated chromatogram (maximum response $c a .55 \mathrm{pA}$ ) and its corresponding two-dimensional contour plot obtained for the analysis of puréed fruit, and highlights the benefit of $\mathrm{GC} \times \mathrm{GC}$ for the improved resolution of a significantly greater number of strawberry volatiles. Vertically aligned contour peaks co-elute on the first column and they are separated on the second. The sensitivity enhancement due to the zone-compression effect increases peak responses. Enantiomers of linalool and 2,5 dimethyl-4-hidroxy- $(2 \mathrm{H})-$ furan-3-one (DMHF) were resolved. The (-)enantiomer of DMHF and the $S$-enantiomer of linalool were tentatively identified as the predominant forms in cultivars Selva and Andina. The compounds benzaldeyde and methyl hexanoate were shown to decrease in post-harvest berries, whilst DMHF and nerolidol increased upon storage.

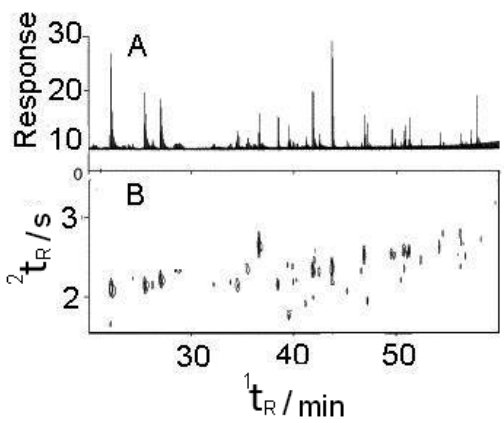

Figure 8. Modulated chromatogram (A) and the corresponding twodimensional contour plot (B) for the analysis of puréed fruit using EtTBS$\beta-C D$ column (Mega, Italy) and CycloSil B column (J\&W Scientific, USA) in the first-dimension. A short section of BPX5 (5\% phenyl polysilphenylene-siloxane) column was used as a trapping column to improve focusing of more volatile compounds between the first-dimension and the most polar second dimension column (BPX50; SGE International, Australia). Adapted from reference 4.
Monoterpenoids play an important role in the differentiation of wine varieties. As monoterpenoids are secondary metabolites whose synthesis is encoded by variety-related genes, the terpenoid profile may be used as a way to trace its varietal origin. ${ }^{47,48}$ Rocha et al. ${ }^{12}$ established monoterpenoids profile of Vitis vinifera L. cv. 'FernãoPires' white grapes by HS-SPME and GC $\times$ GC TOFMS. Using 1D-GC only 26 compounds were detected. The $\mathrm{GC} \times \mathrm{GC}$ total ion chromatogram exhibited several hundreds of peaks, but only monoterpenoids were identified. Fifty six monoterpenoids were found and thereof 20 were reported for the first time in grapes. The combination of the non-polar column in first-dimension with polar column in second dimension allowed the formation of clusters: the monoterpene hydrocarbons and the monoterpene oxygen-containing compounds (Figure 9). However, subclusters were observed within the monoterpene oxygencontaining compounds: oxides, alcohols (monoterpenols and monoterpendiols), aldehydes, esters and ketones. Remarkable results were also obtained in terms of compound classification based on the organized structure of the peaks in structurally-related compounds on the $\mathrm{GC} \times \mathrm{GC}$ contour plot.

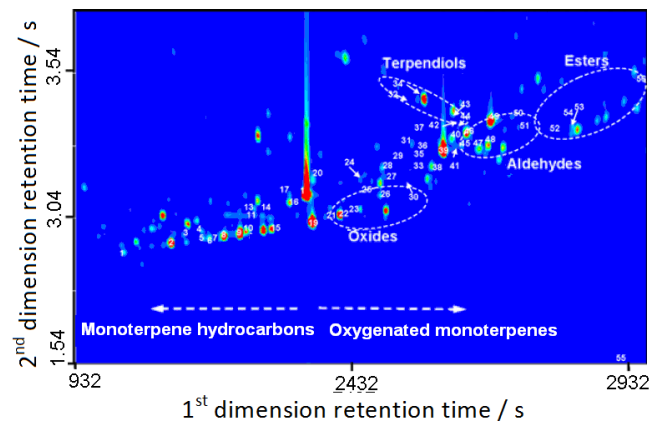

Figure 9. GC $\times \mathrm{GC}$ extracted ion chromatogram contour plot of $\mathrm{m} / \mathrm{z}, 93$, 121 and 136. Bands or clusters formed by structurally related compounds are indicated. Adapted from reference 12.

An image processing approach originating from the proteomics field or DNA array analysis has been transferred successfully to the processing of data obtained with GC $\times$ GC-TOFMS analysis. This approach described by Schmarr and Bernhadt ${ }^{49}$ has proven to be a useful analytical tool for comparison or profiling analysis of volatiles of apple, pear and quince fruit. The date obtained from $\mathrm{GC} \times \mathrm{GC}$ chromatograms were used as contour plots which were converted to gray-scale images and analyzed utilizing a workflow derived from 2D-gel based proteomics. The GC $\times \mathrm{GC}$ images were then merged into a fusion image yielding a defined and project-wide spot consensus pattern. Within detected spot boundaries of this consensus pattern, relative quantities of the volatiles of each $\mathrm{GC} \times \mathrm{GC}$ image 
has been calculated, resulting in more than 700 gap free volatile profiles over all samples. These profiles were used for multivariate statistical analysis and they allowed the clustering of comparable sample origins and prediction of unknown samples. With this method (Figure 10), samples were clearly cluster according to their species. Apples, pears and quince cluster distant from each other and in some cases also according to their cultivars. "Alexander", "Lucas" and "Conference" were distinguished among pears cultivars. "Braeburn" and "Fuji" were not separated but "Elstar", "Gala" and "Pinova" can be distinguished among apples.

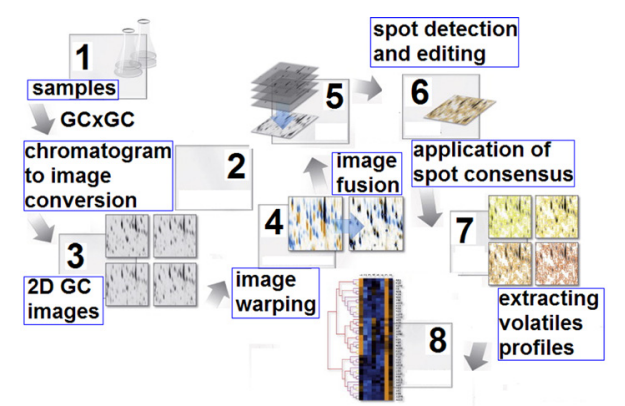

Figure 10. Workflow (adapted) of the described method of Schmarr and Bernhardt. $^{49}$ (1) Volatiles were exctracted by HS-SPME and analysed by GCxGC-qMS; (2) 2D GC chromatograms were transformed into 32-bit images; (3) 2D GC images were stored in Delta2D; (4) Positional correction (warp vectors) resulted in image congruency (dual channel overlay color code: blue $=$ image 1 , orange $=$ image 2 and black $=$ overlap); (5) Volatiles map as a result of project-wide 2D GC image fusion; (6) Detected spot consensus; (7) Spot consensus boundaries were applied to all 2D GC images for gray level integration; (8) Gray level integration results in quantitative data which can be summarized in volatile profiles (blue low amount, black - average amount, orange - large amount of volatile).

\subsection{Dairy products}

The chemical analysis of flavour in dairy products is complicated by the heterogeneous nature of milk. Significant levels of lipids, proteins and carbohydrates in milk make it difficult to separate flavour-active chemicals based on general properties like polarity or volatility. The flavouring compounds vary according to sample state, so that raw milk shows a distinct odor when compared with that of heated or processed milk. For example, esters are responsible for the flavour of raw milk samples, while lactones and heterocyclic compounds are present in heattreated and pasteurized milk. On the other hand, fermented dairy products, such as cheese and yogurt are characterized by the presence of fatty acids which are products of hydrolysis. ${ }^{50}$

Adahchour et al. ${ }^{51}$ analyzed the flavour of dairy sour cream. The analytes were extracted with diethyl ether and subjected to solvent-assisted flavour evaporation (SAFE). A non-polar (CP-SIL 5) and polar (BPX-50) column set and GC $\times$ GC-TOFMS were used. Methional and sotolon are found in dairy products and they are trace-level key compounds, which are very important for olfactory reasons. In 1D-GC chromatogram, both were found to co-elute with intense major peaks (2-heptanone and 2-nonanone, respectively) (Figure 11). As a consequence, it is not possible to positively identify the two trace components by 1D-GC, although this separation has been accomplished by using GC×GC/TOFMS. The improved separation of analytes from each other and - even more important - from interfering matrix compounds makes the quality of mass spectra obtained from GCXGC/TOFMS much better than the one resulting from GC/TOFMS.

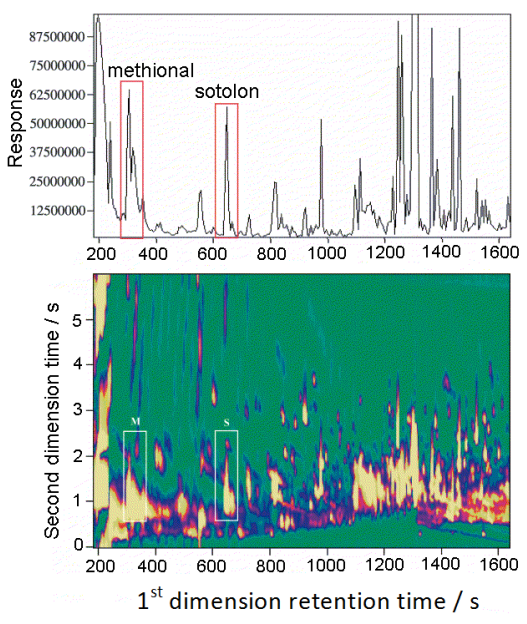

Figure 11. GC $\times$ GC/TOFMS total ion chromatogram of a dairy spread extract: (top) 1D-GC-TOFMS and (bottom) GC $\times$ GC color plot. Regions marked as $\mathrm{M}$ and $\mathrm{S}$ are the elution regions of methional and sotolon, respectively. Adapted from Adahchour et al. 2003. ${ }^{51}$

Butter flavour results from the contribution of several compounds, belonging to different chemical classes, in a delicate balance. The typical flavour of good-quality butter depends on several factors such as the raw material, metabolic activity of bacteria used as starters, processing employed in its production and refrigerating temperature used during the storage..$^{52}$

The potential of GC $\times$ GC-FID and GC $\times$ GC-TOFMS were compared with that of $1 \mathrm{D}-\mathrm{GC}$ for determination of flavour compounds in butter. The volatiles were extracted by using HS-SPME. Several classes of compounds were detected and identified in butter samples, including aldehydes, 2-enals, ketones, fatty acids and lactones. Butter samples were also analyzed after heat treatment. Furan derivatives and heterocyclic compounds such as pyrroles and pyridines were exclusively found in the heat treated samples. A problem found in the 1D-GC study was the failed identification of several compounds having $\mathrm{m} / \mathrm{z}, 99$ and 71 as their major ions, due to separation and 
detectability problems. With GC×GC-TOFMS, these compounds were found to be $\delta$-lactones, while in $1 \mathrm{D}-\mathrm{GC}$ they were identified as unknowns. The authors concluded that the main advantages of $\mathrm{GC} \times \mathrm{GC}$ in comparison with 1D-GC were a more reliable analysis of target compounds, the rapid recognition of prominent classes of compounds on the basis of ordered structures and the provisional identification of a much larger number of unknown compounds. $^{2}$

\subsection{Honey}

Traditionally, the botanical and geographical origin of honey is determined by microscopic analysis of its pollen, ${ }^{53}$ however this strategy is time-consuming. In honey characterization other parameters are also considered, such as moisture, 5-(hydroxymethyl)furan-2-carbaldehyde content, invertase and diastase activity, sugar composition, electrical conductivity, proline content and composition of volatiles. These parameters are known to vary widely with floral and geographical origin. ${ }^{54}$

HS-SPME with a divinylbenzene/carboxenpolydimethylsiloxane (DVB/CAR/PDMS) 50/30 $\mu \mathrm{m}$ fiber followed by $\mathrm{GC} \times \mathrm{GC}$-TOFMS were used for the analysis of honey volatiles by Cajka et al. ${ }^{55}$ Identification of 164 volatile compounds was accomplished using a DB-5ms $\times$ Supelcowax 10 column set during a 19 min run. In 1D-GC analysis, a peak was identified as 3-methyl-cyclopentanol. However, using $\mathrm{GC} \times \mathrm{GC}$ this compound was observed to be a co-elution of two individual compounds, which were identified as hotrienol and nonanal. Alcohols, aldehydes, ketones and ethers represented the main group of honey volatiles. The floral honey samples of Carpentras and Corsica were differentiated by $\mathrm{GC} \times \mathrm{GC}$ chromatogram profiles. Carpentras sample contained mainly compounds as aldehydes (hexanal, heptanal, octanal and nonanal) and alcohols (hexan-1-ol and heptan-1-ol). The intensity of signals belonging to these compounds was significantly lower in the Corsica sample, which, on the other hand, contained higher amounts of lilac aldehyde isomers.

The possibility of verifying the geographical origin of honeys based on the volatile profile using HS-SPME and $\mathrm{GC} \times \mathrm{GC} / \mathrm{TOFMS}$ was investigated by Stanimirova $e t$ $a l .{ }^{56} \mathrm{~A}$ DVB/CAR/PDMS coating was used for volatiles extraction. The column set comprised a non-polar $(5 \%$ phenyl polysilphenylenesiloxane) as primary column and a polar (polyethylene glycol) in the second column dimension. In total, 26 aroma compounds (markers) were selected on the basis of an examination of the $\mathrm{GC} \times \mathrm{GC}$ chromatograms of honey samples by identification of the peaks that significantly varied in their intensity or those that described the quality of the honeys. After the analytical information was collected, pattern recognition techniques were applied to construct classification/discrimination rules to predict the origin of samples on the basis of their volatile profiles. The best performance was achieved by the support vector machines (SVM) method. The volatile profile of Corsican honeys were specific enough and allowed their discrimination from honeys of different geographical origins.

\subsection{Olive oil}

Olive oil quality is dependent on region, variety, the degree of maturation of olives, sanitary conditions, processing/extraction technology as well as storage conditions. However, processing is, in fact, a major factor affecting olive oil quality. ${ }^{57,58}$

Vaz-Freire et $a .^{7}{ }^{7}$ evaluated two different extraction technologies for olive oil production: - decanter and pressing by hydraulic press - using volatile compounds analysis made by HS-SPME-GC $\times$ GC-TOFMS. The volatile compounds of both extraction technologies were compared using statistical image treatment, by means of ImageJ software, for fingerprint recognition and compared with principal component analysis when the area of each chromatographic spot of the contour plots were considered. The resulting contour plots of each sample were divided into quadrants with the same size (Figure 12). Through this division the pixels quantity, which reflects the presence of the different compounds, was quantified for each of the 12 quadrants using ImageJ software. When the individual peak areas were considered, more than $75 \%$ of the total variance was explained by the first two principal components while $84 \%$ was explained when ImageJ software is used. This work showed that statistical treatment of images through software helps achieving a more accurate speciation. In this case, ImageJ software was a quick and clear alternative to extract correct information from contour plots when fingerprinting was

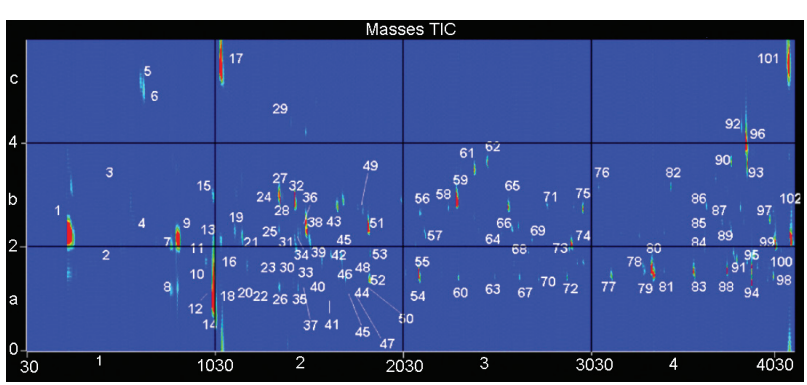

Figure 12. Example of a contour plot obtained for the olive variety Cobrançosa obtained by hydraulic press, divided by quadrants according to volatility ( $\left.{ }^{1} \mathrm{D}\right)$ (from 30 to $4030 \mathrm{~s}$, sections $\left.1-4\right)$ and polarity $\left({ }^{2} \mathrm{D}\right)(0$ to 6 s sections a-c). Adapted from reference 7. 
the main objective. This study allowed the differentiation of two extraction technologies employed to produce olive oil by means of volatile compounds without the necessity of a full identification of all the compounds present in each contour plot.

The potential of non-orthogonal approach in $\mathrm{GC} \times \mathrm{GC}$ were compared to those of the orthogonal approach for olive oil using FID detection by Adahchour et al. ${ }^{29}$ The orthogonal yields better results for relatively non-polar analytes. These are retained less strongly than other sample constituents in the second dimension and show up as a band between 0.3 and $1.5 \mathrm{~s}$ in the chromatogram (Figure 13). In most instances, this creates an efficient separation from the polar matrix. However, Figure 13a shows that co-elution with polar compounds showing wrap-around is a distinct drawback (i.e., the elongated spots eluting in the 20-25. The non-orthogonal approach, on the other hand, is more suitable for more polar analytes. They are retained relatively strongly on the first column, which causes separation from the non-polar sample constituents.

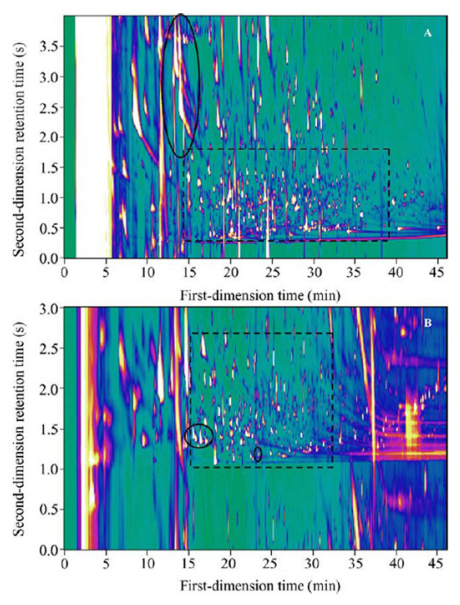

Figure 13. GC $\times$ GC-FID chromatograms of an olive oil extract obtained with (A) orthogonal and (B) non-orthogonal approach. The circled spots show 3-methylbutanoic acid and the three alcohols, 1-hexanol, cis-3hexenol and trans-2-hexenol. The zones marked by dashed lines delineate mainly non-polar analytes in (A) and polar analytes in (B). Adapted from reference 29 .

Olive oil volatiles were analyzed by one dimensional gas chromatography-ion trap mass spectrometry (GCITMS) and results were compared with those generated by GCxGC/TOFMS. Forty-four markers were selected for characterization of 914 samples collected in Italy, Spain, France, Greece, Cyprus and Turkey with the aim to distinguish the olive oils labeled as "Ligurian" (protected denomination of origin region) from all the others ("nonLigurian"). The identification of some volatiles in GCITMS was only tentative since spectral match was not clear enough. Two set-ups were tested for GC×GC and 26 volatiles identified by $\mathrm{GC} \times \mathrm{GC}$ could not be identified using 1D-GC. Highly polar analytes (e.g. formic and acetic acid) were strongly retained in the non-polar $\times$ polar column set-up and this might lead to co-elutions of broad wraparound peaks with peaks eluting in their own modulation cycle. Polar $\times$ medium-polar column combination avoided wrap-around of some peaks. The linear discriminat analysis (LDA) presented a relatively high sensitivity $(89.9 \%)$ but a quite low selectivity (58.2\%), and this model was able to identify most of "Ligurian" samples. However, its ability to classify the "non-Ligurian" samples was small. To overcome this limitation, an artificial neural network (ANN) model was employed, in which quite high sensitivity and selectivity ( $84.1 \%$ and $80.7 \%$, respectively) was obtained. The authors concluded that there was a $20 \%$ possibility for this model to reject a "Ligurian" samples or falsely accept a "non-Ligurian" sample, meaning that this technique may be used as a screening tool. ${ }^{59}$

\subsection{Hazelnut}

Roasting process control is fundamental to optimize flavour, color and texture, as it induces several chemical reactions. These reactions involve specific precursors following known and unknown pathways, to originate a complex mixture of substances, most of them contributing to the total flavour: furans, pyrazines, ketones, alcohols, aldehydes, esters, pyrroles, thiophenes, sulfur compounds, aromatic compounds, phenols, pyridines, thiazoles, oxazoles, lactones, alkanes, alkenes, and acids. ${ }^{16}$

Cordero et al. ${ }^{16}$ studied the volatile fraction of roasted hazelnut samples by using $\mathrm{GC} \times \mathrm{GC} / \mathrm{qMS}$, using HS-SPME with a DVB/CAR/PDMS 50/30 $\mu$ m fiber as sampling technique. The high-complexity sample profiles were interpreted through different methods: a grouptype characterization, a direct fingerprint comparison and a template matching to extract useful and consistent information of samples. In group-type characterization, a suitable number of markers (targets) classified as a function of their significance for the purpose of describing botanical, technological, and sensory characteristics of the samples were selected. Direct fingerprint comparison consists of subtracting a sample or analyzed metadata from a reference metadata set. The template matching consists of a pattern matching in which markers, or more generally separated analytes, of an unknown sample are identified in their GCxGC pattern by matching them to the corresponding reference peaks in the pattern of a reference sample (reference pattern). The group-type analysis, focused on several known botanical and technological markers, enabled sample comparison and characterization based 
on their qualitative and quantitative distribution. Besides, group-type approach is easy to apply, even without specific software. Fingerprint approaches (i.e., direct fingerprint comparison and template matching), on the other hand, extended sample comparisons and correlations to the whole volatiles offering an increased discrimination potential and improved sensitivity due to the wider analyte pattern considered.

\subsection{Cacao}

The quality of a finished chocolate depends largely on the initial quality of the raw materials employed to its production, mainly cacao beans. GC $\times$ GC-TOFMS was used to analyze cacao beans submitted to dry and high moisture conditions during storage. For the HS-SPME procedure, a PDMS/DVB fiber was used and a nonpolar $\times$ polar column set was used in $\mathrm{GC} \times \mathrm{GC}$-TOFMS analysis. Some peaks were found to change as a function of storage conditions with Fischer-ration analysis. Four analytes (acetic acid, nonanal, tetramethyl pyrazine and trymethyl pyrazine) were selected for quantification. Higher concentrations of acetic acid and nonanal were found in samples without evident mold on the bean surface, while the two pyrazines were found in higher quantities when mold was evident on the bean surface. Besides, it was observed that acetic acid presented large levels in dry beans and was absent or in low level under higher moisture conditions. ${ }^{60}$

\subsection{Roast beef}

The flavour of the cooked meat is predominantly derived from Maillard reactions and from the degradation and oxidation of lipids. Heterocyclic compounds, especially those containing sulfur, are important flavour compounds produced in the Maillard reaction providing savory, meaty, roast and boiled flavours. Cooking methods, such as roasting, frying or grilling, as also boiling, smoking or reheating influence flavour formation. Moreover, the temperature reached during the cooking process may have considerable effects on the profile of the formed compounds. Further aspects including meat origin, amino acid ratio, fatty acids and sugars as well as animal diet are important for flavour. ${ }^{61}$

Rochat et al. ${ }^{8}$ used GC $\times \mathrm{GC} / \mathrm{TOFMS}$ to identify sulphur $(S)$-containing compounds from the in-oven roasted beef aroma. The polydimethylsiloxane $100 \mu \mathrm{m}$ (PDMS) SPME fiber was inserted in the condenser to extract the volatiles from vapors during the cooking. Subclasses of thiols, sulphides, thiophenes and thiazoles were clearly distinguished. To overcome the absence of many retention indices in databanks, the missing values were simulated using a multiple linear regression to help the peak identification. This simulation allowed the selection of the best candidates from the hit list generated by the MS software. However the accuracy of the simulation is insufficient to choose between different potential positional isomers. The authors combined GC $\times \mathrm{GC} / \mathrm{TOFMS}$ and GCSNIF analysis which led to the positive identification of six impact sulphur odorants in roast beef.

\subsection{Pepper}

Peppers are economically important due to the vast consumption of diverse varieties. The food industry is the largest user of peppers, where they are used as coloring and flavouring agents in sauces, soups, processed meats, snacks, candies, soft drinks and alcoholic beverages. ${ }^{62}$

The headspace of 13 pepper and peppercorn samples of different species were analyzed by using GC $\times$ GC-FID, GC $\times$ GC-qMS and GC $\times$ GC-TOFMS by Cardeal et al. ${ }^{63}$ The volatile organic compounds were extracted by SPME using a $75 \mu \mathrm{m}$ polydimethylsiloxane/divinylbenzene (PDMS/DVB) fiber. Direct comparison of the GC $\times$ GC-FID and $\mathrm{GC} \times \mathrm{GC} / \mathrm{qMS}$ results revealed the possibility of fingerprinting studies which facilitated sample-to-sample comparison and compound identification. When using GC $\times$ GC/TOFMS, about five times more peaks were identified than in $\mathrm{GC} \times \mathrm{GC} / \mathrm{qMS}$. In Brazilian pepper, more than 700 compounds were identified by $\mathrm{GC} \times \mathrm{GC} / \mathrm{TOFMS}$, the great majority in trace amounts, as against only 139 in the case of $\mathrm{GC} \times \mathrm{GC} / \mathrm{qMS}$.

\subsection{Basil}

Basil (Ocimum basilicum L.) leaves contain distinctive aroma which can be used both fresh and dried to spice up various kinds of meal. The cultivar, agronomical practices and environmental conditions affect the volatile composition of basil. ${ }^{64}$

Klimanková et al. ${ }^{65}$ used DVB/CAR/PDMS 50/30 $\mu \mathrm{m}$ SPME fiber, gas chromatography/ion trap mass spectrometry (GC/ITMS) and GC $\times$ GC/TOFMS to evaluate the volatile profile of basil leaves. More than 60 compounds isolated by HS-SPME method were detected in GC/ITMS, of which 23 were identified. The GC $\times$ GC-TOFMS with nonpolar $\times$ polar column set allowed the identification of minor volatiles that were not identified with GC-ITMS. Comparison of $\mathrm{GC} \times \mathrm{GC}$ chromatograms proved the existence of differences between conventional and ecological cultivars. Linalool, methyl chavicol, eugenol, 
bergamotene and methyl cinnamate were the dominant volatile components, the relative content of each one was found to enable differentiating between the cultivars examined.

\section{Conclusions}

The high peak capacity, enhanced separation power, associated with higher sensitivity and orderly distributed compounds in the separation space have made GC $\times$ GC a very suitable technique for a more detailed and accurate analysis of complex samples, such as food and beverages. The classical nonpolar $\times$ polar column combination is the most used to obtain orthogonal conditions, but polar first-dimension columns have attracted attention because of the improved peak shapes obtained for polar compounds. Examples covered in this review illustrate that $\mathrm{GC} \times \mathrm{GC} / \mathrm{TOFMS}$ has already elucidated the volatile composition of several types of foods and beverages. This is due to advantages presented by this technique over traditional 1D-GC separations, as GC $\times$ GC usually unravels a higher number of chromatographic peaks, facilitates the separation among analytes and interfering compounds of complex matrices, leading to a higher quality mass spectrum of those compounds that would formerly be misidentified due to co-elution in 1D-GC. The possibility of identifying aroma-active trace compounds is also an important feature of $\mathrm{GC} \times \mathrm{GC}$ application to food and beverage samples. This information can be used for fingerprinting, and the differentiation of plants of distinct varieties, cultivars, and geographical origin, detection of adulterations, control of production and technological processes and other applications. Fingerprint and group type comparison using different approaches and softwares proved to be extremely useful as they help to differentiate among different samples, and are a promising field for the future applications of $\mathrm{GC} \times \mathrm{GC}$ to the analysis of volatiles in foods and beverages. As a future perspective, the analysis of volatile and semivolatile compounds of a greater number of food and beverage samples by $\mathrm{GC} \times \mathrm{GC}$ will certainly be beneficial as it will bring an enormous amount of new information, which would not be possible to achieve using only 1D-GC.

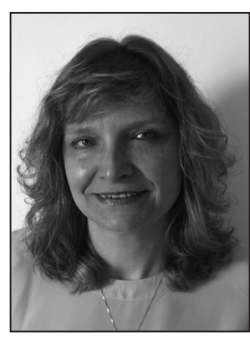

Claudia Alcaraz Zini is currently a professor at the Institute of Chemistry, Federal University of Rio Grande do Sul (UFRGS). She got her Master degree in Chemistry also from the UFRGS and her PhD studies were developed at the University of Waterloo $(U W)$ in Canada, in a joint project between UW and UFRGS. There, she worked with solid phase microextraction applied to in vivo and in vitro sampling of plants volatiles. Claudia works with Analytical Chemistry, especially in the fields of separation science, focusing on chromatography and extraction techniques. Her main interests at the moment are comprehensive two-dimensional gas chromatography applied to complex mixtures, such as petroleum, coal, plants, food and beverage aromas, and environmental matrices.

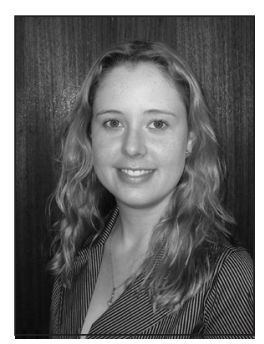

Juliane Elisa Welke is an Assistant Professor at the Federal Institute of Education, Science and Technology Farroupilha. She graduated in Industrial Chemistry at the Federal University of Rio Grande do Sul (UFRGS) in 2006. She received her Master degree also from the Federal University of Rio Grande do Sul (UFRGS) in 2008 and is currently a PhD student at the Institute of Chemistry, UFRGS, working with comprehensive two-dimensional gas chromatography applied to flavour analysis.

\section{References}

1. Laing, D. G.; Jinks, A.; Trends Food Sci. Technol. 1996, 7, 387.

2. Adahchour, M.; Wiewel, J.; Verdel, R.; Vreuls, R. J. J.; Brinkman, U. A. T.; J. Chromatogr., A 2005, 1086, 99.

3. Cardeal, Z. L.; Souza, P. P.; Gomes da Silva, M. D. R.; Marriott, P. J.; Talanta 2008, 74, 793.

4. Williams, A.; Ryan, D.; Guasca, A. O.; Marriott, P. J.; Pang, E.; J. Chromatogr., B 2005, 817, 97.

5. Ryan, D.; Shellie, R.; Tranchida, P. Q.; Casilli, A.; Mondello, L.; Marriott, P. J.; J. Chromatogr., A 2004, 1054, 57.

6. Whitfield, F. B.; Int. J. Food Sci. Technol. 1998, 33, 31.

7. Vaz-Freire, L. T.; da Silva, M. D. R. G.; Freitas, A. M. C.; Anal. Chim. Acta 2009, 633, 263.

8. Rochat, S.; Laumer, J.-Y. S.; Chaintreau, A.; J. Chromatogr., A 2007, 1147, 85.

9. Castro, R.; Natera, R.; Durán, E.; García-Barroso, C.; Eur. Food Res. Technol. 2008, 228, 1.

10. Schoenmakers, P.; Marriott, P.; Beens, J.; LC GC Eur. 2003, 335.

11. Bianchi, F.; Careri, M.; Conti, C.; Musci, M.; Vreuls, R.; J. Sep. Sci. 2007, 30, 527.

12. Rocha, S. M.; Coelho, E.; Zrostlíková, J.; Delgadillo, I.; Coimbra, M. A.; J. Chromatogr., A 2007, 1161, 292.

13. Schomburg, G.; J. Chromatogr., A 1995, 703, 309.

14. Adahchour, M.; Beens, J.; Brinkman, U. A. T.; J. Chromatogr., $A$ 2008, 1186, 67. 
15. Beens, J.; Brinkman, U. A. T.; Analyst 2005, 130, 123.

16. Cordero, C.; Bicchi, C.; Rubiolo, P.; J. Agric. Food Chem. 2008, 56,7655 .

17. Liu, Z.; Phillips, J. B.; J. Chromatogr. Sci. 1991, 29, 227.

18. Górecki, T.; Panić, O.; Oldridge, N.; J. Liq. Chromatogr. Related Technol. 2006, 29, 1077.

19. Pursch, M.; Sun, K.; Winniford, B.; Cortes, H.; Weber, A.; McCabe, T.; Luong, J.; Anal. Bioanal. Chem. 2002, 373, 356.

20. Khummueng, W.; Harynuk, J.; Marriott, P. J.; Anal. Chem. 2006, $78,4578$.

21. Ledford, E. B.; Billesbach, C.; J. High Res. Chromatogr. 2000, 23,202

22. Harynuk, J.; Górecki, T.; Campbell, C.; $L C-G C N$. Am. 2002, 20, 876.

23. Begnaud, F.; Debonneville, C.; Probst, J.-P.; Chaintreau, A.; Morrison, P. D.; Adcock, J. L.; Marriott, P. J.; J. Sep. Sci. 2009, $32,3144$.

24. Kallio, M.; Jussila, M.; Raimi, P.; Hyötyläinen, T.; Anal. Bioanal. Chem. 2008, 391, 2357.

25. Shellie, R. A.; Xie, L.; Marriott, P. J.; J. Chromatogr., A 2002, 968, 161.

26. Marriott, P. J.; Shellie, R.; Trends Anal. Chem. 2002, 21, 573.

27. Mayadunne, R.; Nguyen, T.; Marriott, P. J.; Anal. Bioanal. Chem. 2005, 382, 836.

28. Ryan, D.; Morrison, P.; Marriott, P. J.; J. Chromatogr., A 2005, $1071,47$.

29. Adahchour, M.; Beens, J.; Vreuls, R. J. J.; Batenburg, A. M.; Brinkman, U. A. T.; J. Chromatogr., A 2004, 1054, 47.

30. Mondello, L.; Casilli, A.; Tranchida, P. Q.; Dugo, P.; Costa, R.; Festa, S.; Dugo, G.; J. Sep. Sci. 2004, 27, 442.

31. Zhu, S.; Lu, X.; Ji, K.; Guo, K.; Li, Y.; Wu, C.; Xu, G.; Anal. Chim. Acta 2007, 597, 340.

32. Cardeal, Z. L.; Marriott, P. J.; Food Chem. 2009, 112, 747.

33. Mondello, L.; Tranchida, P. Q.; Dugo, P.; Dugo, G.; Mass Spectrom. Rev. 2008, 27, 101.

34. Ryan, D.; Watkins, P.; Smith, J.; Allen, M.; Marriott, P. J.; J. Sep. Sci. 2005, 28, 1075.

35. Dalluge, J.; Beens, J.; Brinkman, U. A. T.; J. Chromatogr., A 2003, 1000, 69.

36. Górecki, T.; Harynuk, J.; Pani, O.; J. Sep. Sci. 2004, 27, 359.

37. Mac Namara, K.; Leardi, R.; Sabuneti, A.; Anal. Chim. Acta 2005, 542, 260 .

38. Allen, M. S.; Lacey, M. J.; Boyd, S. J.; J. Agric. Food Chem. 1995, 43, 769.

39. Ryona, I.; Pan, B. S.; Sacks, G. L.; J. Agric. Food Chem. 2009, 57,8250 .

40. Komura, H.; J. Sep. Sci. 2006, 29, 2350.
41. Fan, W.; Qian, M. C.; Flavour Fragr. J. 2006, 21, 333.

42. Souza, P. P.; Cardeal, Z. D.; Augusti, R.; Morrison, P.; Marriott, P. J. J. Chromatogr. A 2009, 1216, 2881

43. Akiyama, M.; Murakami, K.; Ikeda, M.; Iwatsuki, K.; Wada, A.; Tokuno, K.; Onishi, M.; Iwabuchi, H.; J. Food Sci. 2007, 72, C388.

44. Shellie, R. A.; Marriott, P. J.; Huie, C. W.; J. Sep. Sci. 2003, 26, 1185.

45. Salunkhe, D. K.; Do, J. Y.; Maga, J. A.; Crit. Rev. Food Sci. Nutr. 1976, 8, 161.

46. Boelens, M. H.; van Gemert, L. J.; Perfum. Flavor. 1993, $18,1$. 47. Mateo, J. J.; Jiménez, M.; J. Chromatogr., A 2000, 881, 557.

48. Martin, D. M.; Bohlmann, J.; Phytochemistry 2004, 65, 1223.

49. Schmarr, H.-G.; Bernhardt, J.; J. Chromatogr., A 2010, 1217, 565.

50. Friedrich, J. E.; Acree, T. E.; Int. Dairy J. 1998, 8, 235.

51. Adahchour, M.; van Stee, L. L. P.; Beensa, J.; Vreulsa, R. J. J.; Batenburgb, M. A.; Brinkmana, U. A. T.; J. Chromatogr., A 2003, 1019, 157 .

52. Povolo, M.; Contarini, G.; J. Chromatogr., A 2003, 985, 117.

53. Fagundez, G. A.; Caccavari, M. A.; Grana 2006, 45, 305.

54. Anklam, E.; Food Chem.; 1998, 63, 549.

55. Cajka, T.; Hajšlova, J.; Cochran, J.; Holadová, K.; Klimánková, E.; J. Sep. Sci. 2007, 30, 534.

56. Stanimirova, I.; Üstün, B.; Cajka, T.; Riddellova, K.; Hajšlova, J.; Buydens, L. M. C.; Walczak, B.; Food Chem. 2010, 118, 171.

57. Vinha, A. F.; Ferreres, F.; Silva, B. M.; Valentão, P.; Gonçalves, A.; Pereira, J. A.; Oliveira, M. B.; Seabra, R. M.; Andrade, P. B.; Food Chem. 2005, 89, 561.

58. Torres, M. M.; Maestri, D. M.; Food Chem. 2006, 96, 507.

59. Cajka, T.; Riddellova, K.; Klimankova, E.; Cerna, M.; Pudil, F.; Hajšlova, J.; Food Chem. 2010, 121, 282.

60. Humston, E. M.; Knowles, J. D.; McShea, A.; Synovec, R. E.; J. Chromatogr., A 2010, 1217, 1963.

61. Mottram, D. S.; Food Chem. 1998, 62, 415.

62. Pino, J.; González, M.; Ceballos, L.; Centurión-Yah, A. R.; Trujillo-Aguirre, J.; Latournerie-Moreno, L.; Sauri-Duch, E.; Food Chem. 2007, 104, 1682.

63. Cardeal, Z. L.; Silva, M. D. R. G.; Marriott, P. J.; Rapid Commun. Mass Spectrom. 2006, 20, 2823.

64. Loughrin, J. H.; Kasperbauer, M. J.; J. Agric. Food Chem. 2003, $51,2272$.

65. Klimánková, E.; Holadová, K.; Hajšlová, J.; Čajka, T.; Poustka, J.; Koudela, M.; Food Chem. 2008, 107, 464.

Submitted: June 25, 2010 Published online: February 17, 2011 